2019-12

Fatigue life prediction for rotary friction

welded Ti-6Al-4V under variable

amplitude fatigue loading

van der Merwe, HB

http://hdl.handle.net/10026.1/15100

10.1016/j.tafmec.2019.102321

Theoretical and Applied Fracture Mechanics

Elsevier

All content in PEARL is protected by copyright law. Author manuscripts are made available in accordance with publisher policies. Please cite only the published version using the details provided on the item record or document. In the absence of an open licence (e.g. Creative Commons), permissions for further reuse of content should be sought from the publisher or author. 


\title{
Fatigue life prediction for rotary friction welded Ti-6Al-4V under variable amplitude fatigue loading
}

\author{
HB van der Merwe ${ }^{1 *}, \mathrm{MN}_{\text {James }}{ }^{1,2}$, DG Hattingh $^{1}$ and W Rall ${ }^{1}$ \\ ${ }^{1}$ Department of Mechanical Engineering, Nelson Mandela Metropolitan University, Port Elizabeth \\ (South Africa) \\ ${ }^{2}$ School of Engineering, University of Plymouth, Plymouth (UK)
}

\section{Abstract}

The present paper considers variable amplitude fatigue lifing for rotary friction welds in Grade 23 6Al-4V titanium alloy. The work reported in this paper aimed firstly at optimising the parameters necessary to successfully rotary weld $6 \mathrm{~mm}$ diameter hourglass specimens of Ti-6Al-4V and, secondly, at generating CA stress-life (S-N) fatigue data to underpin a VA fatigue life prediction that was then experimentally verified against the results obtained from VA fatigue testing using an 3,200 turning point sequence extracted from the simulated aircraft load spectrum mini-FALSTAFF (a modified Fighter Aircraft Loading Standard for Fatigue). It was found that the real damage sum $D_{\text {real }}=\left(D_{\text {spec }} / L_{s}\right) * \bar{N}_{\text {exper. }}$ was significantly $<1.0$ for both parent alloy and welded specimens and also varied with maximum stress amplitude. Taking a damage sum value of 1.0 as representing failure in fatigue life prediction would therefore be grossly nonconservative for these Grade $236 \mathrm{Al}-4 \mathrm{~V}$ titanium specimens under spectrum VA loading, irrespective of whether they are in the parent plate or rotary friction welded condition.

Keywords: rotary friction welds; Ti-6Al-4V alloy; Variable Amplitude spectrum loading; Gassner line; fatigue life prediction

Declaration of interest: None.

Funding: This work was supported by the Titanium Centre of Competence. 


\section{Nomenclature}

$\begin{array}{ll}\sigma / S & \text { Stress } \\ \Delta \sigma & \text { Stress range } \\ \mathrm{R}\left(\sigma_{a} / \sigma_{\mathrm{m}}\right) & \text { Stress ratio } \\ \overline{\mathrm{R}} & \text { Load ratio } \\ \mathrm{P}_{\mathrm{f}} & \text { Failure probability } \\ N & \text { Number of constant amplitude cycles } \\ \bar{N} & \text { Number of variable amplitude cycles } \\ N_{f} & \text { Number of cycles to failure } \\ N_{\text {exp }} & \text { Experimental cycles to failure } \\ N_{\text {calc }} & \text { Predicted cycles to failure } \\ \mathrm{P}_{\mathrm{f}} & \text { Probability of failure } \\ \mathrm{n} & \text { Number of cycles at applied stress level } \\ D & \text { Accumulated damage sum } \\ D_{s p e c} & \text { Damage accumulation spectrum sum } \\ D_{\text {real }} & \text { Real damage accumulation sum } \\ L_{s} & \text { Variable amplitude sequence length } \\ \mathrm{upset} & \text { Length consumed during welding process } \\ \mathrm{f} & \text { Frequency } \\ \mathrm{R}_{a} & \text { Average surface roughness } \\ \mathrm{HV} & \text { Vickers pyramid number }\end{array}$




\section{Introduction}

Within the aerospace and automotive industrial sectors there is a global drive toward lightweight design and hence, as noted by Sonsino et al [1], "vehicle development without experimental and numerical consideration of variable amplitude loading would be unthinkable". This means that prototype components usually undergo a rigorous design and development process that includes variable amplitude (VA) fatigue testing using a load spectrum applicable to the specific component. Complexities are introduced into the fatigue design process from the necessary assumptions regarding the various load 'states', i.e. combinations of load and cyclic duration experienced in the required design lifetime, and the fact that constant amplitude (CA) fatigue design curves are generally used in the fatigue analysis. Once a representative and statistically reliable load spectrum has been determined, the fatigue design process therefore usually invokes the Rainflow cycle counting technique to reduce the long-term spectrum of varying stress into a stress histogram that consists of a convenient number of equivalent constant stress range blocks $\Delta \sigma_{i}$ each containing a number of stress repetitions $n_{i}$. Cycle counting techniques allow the cumulative fatigue damage to be summed linearly through the application of the Palmgren-Miner equation, and this introduces the potential for further errors from load sequence effects that are known to have an influence on fatigue life [2].

In this process failure is assumed to occur when the damage sum equals unity. However, extensive fatigue testing has demonstrated that failure can occur at damage sum values lying between 0.1 to $10[3,4]$. The situation is further complicated for the case of solid-state rotary friction welds as, to date, there are no standards that specifically provide fatigue design curve guidance as a function of weld detail geometry and alloy for solid state, friction welds. However, a recent paper by Maggiolini et al [5] has shown that friction stir welds in aluminium alloys have fatigue strength values generally significantly higher than the values recommended by current fusion weld standards, e.g. Eurocode 9 [6] or IIW [7]. It is therefore clear that additional work on the fatigue design of solid state friction welds is both necessary and useful. This paper provides data on rotary solid state friction welds.

Rotary solid-state friction welding is used to join metals and thermoplastics in a variety of aviation and automotive applications. It offers a number of significant advantages compared with fusion welding techniques, including fast joining times, small heat-affected zones (HAZ) with good properties, and lower joint preparation requirements because surface contaminants are removed during welding through a combination of rotary motion and forging (or upsetting) force [8]. It is also possible to join dissimilar materials, which is a particular advantage in the aerospace industry. 
The present paper considers variable amplitude fatigue lifing for rotary friction welds in Ti$6 \mathrm{Al}-4 \mathrm{~V}$ alloy. Ti-6Al-4V is an $\alpha-\beta$ titanium alloy that combines high strength, low weight and excellent corrosion resistance. It is one of the most widely used titanium alloys and has an extensive range of applications where low density and excellent corrosion resistance are necessary, e.g. in the aerospace industry and in biomedical applications for implants and prostheses. The titanium used in this work was a Grade 23 alloy with extra-low interstitial content supplied as $14 \mathrm{~mm}$ diameter bar in the annealed condition $\left(760^{\circ} \mathrm{C}\right.$ for 1 hour $)$ with the composition and tensile properties given in Table 1 .

The work reported in this paper was aimed, firstly, at optimising the parameters necessary to successful rotary weld $6 \mathrm{~mm}$ diameter hourglass specimens of Ti-6Al-4V and, secondly, at generating CA stress-life (S-N) fatigue data to underpin a VA fatigue life prediction that was then experimentally verified against the results obtained from VA fatigue testing using an extract from the simulated aircraft load spectrum mini-FALSTAFF (a modified Fighter Aircraft Loading Standard for Fatigue [9, 10]).

The results obtained provide useful information to support VA fatigue design for rotary friction welded components.

\section{Rotary Friction Welding of Fatigue Specimens}

A bespoke multipurpose friction processing platform, termed WeldCore 3, developed at Nelson Mandela University was used for the rotary friction welding (Figure 1), while Figure 2 shows details of the titanium specimen geometry and the rotary friction joint in a typical specimen. Figure 3 provides a more detailed illustration of the grip arrangement used to weld the two halves of the specimens together. Note that in Figure 3 the specimen halves are termed 'studs'. The main operating parameters of the WeldCore 3 platform are a maximum speed of 5,250 rpm, axial forging force of $40 \mathrm{kN}$ and a torque of $60 \mathrm{Nm}$. The rotating spindle can come to a complete stop in $0.2 \mathrm{~s}$ which assists in welding small diameter components. A Human Machine Interface (HMI) is used to monitor, control and change the process parameters during the welding process. Force, time, rotational speed, spindle torque and translated axial distance data can all be logged during welding. The transmitted torque experienced by the load cell (see Figure 9) is recorded separately.

The starting point for determining the optimum rotary friction welding (RFW) process parameters was work done by Tsikayi [11] which identified that appropriate values of the axial force and forging force were $4 \mathrm{kN}$ and $6 \mathrm{kN}$ respectively. Table 2 gives the values of upset distance and rotation speed that were trialled in the present work. Optimisation 
involved checking the microstructure and mechanical properties against the unwelded titanium alloy, as well as visual inspection for defects. Once an optimum set of weld parameters was identified all fatigue specimens were welded using them. Post weld specimen preparation included machining away of the flash produced during welding, machining away the stud shoulders and re-machining the correct specimen radius. The specimens were then polished with a final finish of 1200 grit paper to obtain an average surface roughness value $R_{a}=0.43 \mu \mathrm{m}$.

Parameter optimisation was carried out in two steps. The influence of upset distance and rotation speed on microstructure and hardness were investigated sequentially. Optimisation aimed to obtain a hardness profile across the weld zone which was similar to that of the parent material. Hardness variations across the weld zone that are too large (approximately $\sim 100 \mathrm{HV}$ ) can lead to early crack initiation from metallurgical notches as well as from microstructural variations.

Upset distance was the first parameter to be considered and specimens $\mathrm{H} 7, \mathrm{H} 9$ and $\mathrm{H} 5$ were welded with a constant rotational speed and different upset distances of $0.5 \mathrm{~mm}, 1.0$ $\mathrm{mm}$ and $1.5 \mathrm{~mm}$, respectively (see Table 2 ). Weld cross-sections were metallurgically examined for flaws. Figure 4 shows a typical macrograph and associated microstructures at 100x magnification for trial H5. No visually discernible differences were observed in the microstructures in trials $\mathrm{H} 5, \mathrm{H} 7$ and $\mathrm{H} 9$. In all cases, the heat affected zone (HAZ) was narrow and no impurities/discontinuities were found. The temperature during welding was below the $\beta$ transus temperature for Grade 23 Ti- $6 \mathrm{Al}-4 \mathrm{~V}$ of $\approx 979^{\circ} \mathrm{C}$ [12]. The $\beta$ transus is the temperature above which only the $\beta$ phase exists. Since an $\alpha+\beta$ structure was observed in the welds it can be deduced that the weld temperature was below the $\beta$ transus temperature. Additionally, the welds were air-cooled, rather than quenched. Figure 5 indicates, on a typical rotary friction welded specimen, where the hardness measurements were made. The hardness data for these trial welds are given in Figure 6 and they indicate that the average hardness across the weld in $\mathrm{H} 5$ (upset $=1.5 \mathrm{~mm} ; 340 \mathrm{HV}$ ) is closest to the parent alloy value of $330 \mathrm{HV}$.

The second parameter to be evaluated was rotational welding speed, using the same process of inspection for defects and hardness measurements. Trials $\mathrm{H} 4, \mathrm{H} 5$ and $\mathrm{H} 6$ were used for this part of the work corresponding with rotation welding speeds of $2,500 \mathrm{rpm}, 3,500$ rpm and 5,000 rpm respectively. The hardness data is presented in Figure 7 where all three trials show very similar results. Tensile tests were therefore carried out to better differentiate between the three rotational speeds and the results are shown in Figure 8 and Table 3. Tensile data for weld $\mathrm{H} 4 \mathrm{t}$ closely follows the elastic portion of the parent alloy stress- 
extension curve in the linear elastic region and slightly overmatches the proof strength.

Welds H5t and H6t show significantly different moduli of elasticity beyond an applied stress of $\approx 400 \mathrm{MPa}$. Changes in modulus of elasticity across the weld zone are important in terms of avoiding metallurgical notches and the parameters used in trial $\mathrm{H} 4$ were therefore adopted for manufacturing the fatigue specimens.

The final weld parameters were therefore identified as a rotational speed of 2,500 rpm, upset distance of $1.5 \mathrm{~mm}$, axial force of $4 \mathrm{kN}$ and upset forging force of $6 \mathrm{kN}$. A typical torque curve measured during the welding process using these final process parameters is given in Figure 9. The rotary friction welding stages identified by Kimura et al [13] are clearly visible. In stage 1 the two weld studs come into contact resulting in wear and seizure at the interface with an accompanying increase in torque. In stage 2 plasticisation occurs and the torque decreases, while in stage 3 the two studs are being pushed together through the upset distance under the applied axial force. In stage 4 the forging force is applied and the spindle is then stopped. The work done by Tsikayi [11] showed that the grain structure is refined during the forging stage and excess material is forced out as a flash around the joint line.

\section{$3 \quad$ Fatigue Testing}

Fatigue testing of both parent alloy and welded specimens was performed on the polished specimens. CA sinusoidal fatigue testing was performed on a Zwick Vibrophore testing machine at room temperature. Tests used a stress ratio $R=-1$ and the system operates at the resonant frequency of the load train and specimen, which for the present specimens was $73 \mathrm{~Hz}$. The specimen alignment was checked so as to limit any unintended bending stresses, and these were found to be $<4.3 \%$ of the applied maximum tensile force in any test. Failure was defined as a frequency change of $2 \mathrm{~Hz}$, reflecting an increased specimen compliance and failure would then follow within several thousand cycles. Run-out for CA specimens was deemed to occur at $2 \times 10^{6}$ load cycles.

VA testing used a final sequence length of $L_{s}=3,200$ turning points extracted from the miniFALSTAFF spectrum. The mini-FALSTAFF spectrum sequence is a shortened version (containing 18,012 turning points) of the FALSTAFF (Fighter Aircraft Loading Standard for Fatigue Evaluation) spectrum containing 35,966 turning points. Limitations on the testing machine software restricted the present work to using an extracted sequence containing 3,200 turning points resulting in a load ratio of $\bar{R}=-0.2667$. For simplicity and repeatability of potential future work, the first 3,200 turning points in the mini-FALSTAFF sequence were used for the present work. Figure 10 shows this 3,200 turning point sequence extracted from the mini-FALSTAFF load spectrum which was applied axially using an Instron 8801 testing 
machine with a frequency of $30 \mathrm{~Hz}$ at room temperature. The Rainflow matrix displaying the distribution of load cycles as a function of load range and mean load is shown in Figure 11. Failure was taken as final rupture and the run-out in the case of the VA specimens was defined at $3 \times 10^{6}$ cycles.

Fatigue testing under VA loading is summarised clearly, in terms of data collection and presentation, in a paper by Sonsino [14] that describes CA testing and the Wöhler S-N curves, as well as VA testing and the Gassner failure line. Using the same terminology as Sonsino, where $N$ and $\bar{N}$ represent, respectively, constant and variable amplitude cycles, the damage sum $D_{\text {spec }}$ corresponding to a single application of the 3,200 turning point spectrum load sequence can be found using the Palmgren-Miner linear damage summation to get:

$$
\sum\left(\frac{n}{N}\right)_{i}=D_{\text {spec }}
$$

The total lifetime damage sum $D_{\text {real }}$ for a given stress amplitude is obtained from the experimental S-N data as:

$$
D_{\text {real }}=D_{\text {spec }} \cdot \frac{\bar{N}_{\text {exp }}}{L_{S}}
$$

where $\bar{N}_{\text {exp }}$ is the experimentally observed number of cycles to failure under the spectrum loading. Equally, a calculated variable amplitude fatigue life can be found from:

$$
\bar{N}_{\text {calc }}=\frac{D_{\text {real }}}{D_{\text {spec }}} L_{S}
$$

Sonsino [14] notes that investigations of cumulative damage show a significant scatter of data with about $90 \%$ of the results lying below the conventional failure value of $D_{\text {real }}=1$. His conclusion was that variable amplitude fatigue testing was necessary to provide proof of structural integrity over the required lifetime.

\section{Fatigue Analysis - Experimental Data}

The results of variable amplitude testing under spectrum loading are presented in the form of a Gassner line that plots amplitude of the spectrum sequence against $\bar{N}_{\text {exp }}$, where the different amplitude levels are obtained through a linear amplification or reduction of all the stress ranges in the spectrum sequence, while the shape and length $L_{s}$ of the spectrum remain independent of the load level [14]. At each load level the life to failure under VA loading is given by $\bar{N}_{i}=x . L_{s}$ where $x$ is the number of repetitions of the spectrum load 
sequence length $L_{s}$ causing failure at the $i^{\text {th }}$ load level. Figure 12 illustrates the fatigue life analysis procedures used in this work for both the CA and VA spectrum loading, while Figure 13 presents the experimental CA and VA data for both the parent titanium alloy and the rotary friction welded specimens. In the CA tests on welded specimens cracks initiated fairly equally in the HAZ (4 cases) and in the parent alloy (3 cases - Table 6). This is interpreted as evidence that the choice of welding parameters, as described in section 2 , is close to optimum in terms of achieving approximately matching hardness values in the weld zone and in the parent alloy. Under VA loading, however, (Table 7) there is a preference for crack initiation to occur in association with the weld region, with only one specimen cracking in the parent alloy and possible reasons for this difference are discussed below. Typical initiation sites and fracture surface appearance are shown in Figures 15-17. The fracture surfaces exhibit an initially flat fracture path, indicative of low-stress high cycle fatigue. As the stress intensity increases during crack propagation, the surfaces become gradually rougher and more fibrous until final fracture occurs at $\pm 45^{\circ}$ to the stress direction [15].

As can be seen in Figure 14, under CA loading the welded specimens have a lower fatigue strength than the parent alloy and the fatigue limit of the welded specimens at $2 \times 10^{6}$ cycles is $530 \mathrm{MPa}$, a reduction of $16.5 \%$ compared with the parent alloy where the fatigue limit is $635 \mathrm{MPa}$ at $2 \times 10^{6}$ cycles. The Basquin S-N curve equations for the CA fatigue results were calculated according to ASTM E 739 [16] using linear regression analysis, and the maximum likelihood method [17] was used to determine probability of failure lines, with runout results being excluded from the analysis:

Parent alloy: $\quad \log (N)=-31.385 \log (S)+93.55$

Rotary welds:

$$
\log (N)=-7.7075 \log (S)+26.12
$$

In the CA tests, the trend lines indicate that the welded specimens would outperform the parent alloy at short fatigue lives, approximately $<10^{4}$ cycles. This reflects the higher tensile strength seen in Figure $8(\mathrm{H} 4)$ for the welded specimens. For polished specimens at short lives, a higher tensile strength generally equates to a higher fatigue strength. At longer lives, where crack initiation (perhaps up to a crack $\sim 0.5 \mathrm{~mm}$ deep) dominates the fatigue life, the finer grain size leads to faster crack growth once a grain size crack is initiated.

Under VA loading the welded specimens show an enhanced life compared with the unwelded specimens at lives approximately $>5.4 \times 10^{5}$ cycles. This is believed to reflect the influence of the overload-induced monotonic plastic zone that creates higher dislocation density and hence barriers to crack propagation across grain boundaries in a larger number of grains than in the parent alloy specimens. The welded specimens also have a finer grain size and fatigue cracks encounter more grain boundaries that are unfavourably orientated with respect to their 
favoured growth direction and this increases the chance that the crack tip is forced to change direction at grain boundaries at multiple points along the crack front, thus reducing the driving force for crack growth [18], compared with the parent alloy specimens subject to the same load spectrum. Hence for the welded specimens under VA loading, the retardation aspects of repeated overload cycles dominate long life performance and extend the life relative to the parent alloy specimens, whereas at shorter lives Figure 14 indicates that the fatigue performance is very similar for the parent alloy and welded specimens.

\section{$5 \quad$ Fatigue Analysis - VA Life Prediction Model}

In many cases, it is advantageous to be able to make a prediction of the fatigue life under variable amplitude loading, particular for components that are already in service. Strain gauges are used to collect spectrum loading data during component operation. This measured strain gauge data can then be used as input into a VA life prediction exercise. In the present work, the life prediction methodology shown in Figure 18 was used, where both welded and parent alloy specimens were subjected to the 3,200 turning point VA loading sequence extracted from the mini-FALSTAFF load spectrum. Strains induced by the VA loading were measured with strain gauges and the data was then used in a Rainflow counting exercise. The Smith, Watson and Topper mean stress correction model was subsequently used to transform the data to zero mean stress $(R=-1)$ so that fully reversed CA S-N data could be used for the VA life prediction using the Palmgren-Miner linear damage summation rule. Equation 1 gives the resulting damage $D_{\text {spec }}$ and substituting $D_{\text {real }}$ into equation 2 gives the value of $\bar{N}_{\text {exp }}$. It is evident that the real damage sum is significantly $<1.0$ for both parent alloy and welded specimens and also varies with maximum stress amplitude in the VA loading sequence. A fatigue life equivalent to a damage sum of 1.0 can also be calculated (this is denoted as $N_{\text {calc }}$, $D_{\text {real }}=1$ in Table 4 ) and this is given by:

$$
\bar{N}_{\text {calc, } D_{\text {real }}=1}=\frac{1.0}{D_{\text {spec }}} L_{S}
$$

The average damage sum $D_{\text {real }}$ in Table 4 for the parent alloy data is 0.6 and for the welded specimens it is 0.51 . Substituting these average values of $D_{\text {real }}$ into equation 2 gives calculated values for the expected fatigue life, that are presented in Table 5 and plotted in Figure 20 on log-log scales. The percentage difference between the calculated and experimentally observed life is now significantly reduced and is generally lower than the predicted value. It is clear that for rotary friction welded components, fatigue life prediction 
based on a damage sum $=1.0$ is highly likely be dangerously nonconservative. Thus VA lifing of such components should take account of the real damage sum obtained from spectrum loading fatigue tests.

\section{Conclusion}

This work initially optimised the rotary friction welding parameters for hourglass fatigue specimens of Grade $236 \mathrm{Al}-4 \mathrm{~V}$ titanium alloy, through a parametric study of the effect of rotational speed and upset distance on hardness, tensile strength and defects. An optimised set of welding parameters were derived as a rotational speed of 2,500 rpm, upset distance of $1.5 \mathrm{~mm}$, axial force of $4 \mathrm{kN}$ and upset forging force of $6 \mathrm{kN}$.

CA and VA fatigue tests were then carried out on polished parent alloy and rotary welded specimens. CA fatigue data was plotted as Wöhler S-N curves and the VA data as Gassner lines. Under CA loading parent alloy specimens generally outperformed welded specimens by a significant margin except at fatigue lives approximately $<10^{4}$ cycles. This improvement in fatigue performance at shorter lives observed for the welded specimens is believed to reflect their higher tensile strength obtained from the chosen friction welding parameters.

The VA fatigue data shows an enhanced fatigue life for welded specimens at longer lives, compared with the unwelded specimens, and this reflects both the influence of a higher dislocation density in a larger number of near-tip grains for the case of the welded specimens subject to overload cycles and an increased number of localised crack front deviations along the crack front as a larger number of unfavourably orientated grains are encountered for a given crack length in the finer grain size weld zone. Both of these effects reduce the effective driving force for crack growth.

It was found that the real damage sum $D_{\text {real }}=\left(D_{\text {spec }} / L_{s}\right) * \bar{N}_{\text {exper. }}$ was significantly $<1.0$ for both parent alloy and welded specimens and also varied with maximum stress amplitude. Using a damage sum value of 1.0 as representing failure in fatigue life prediction would be dangerously nonconservative for these Grade $236 \mathrm{Al}-4 \mathrm{~V}$ specimens under spectrum VA loading, whether in the parent plate or rotary friction welded condition. For the parent alloy, the predicted lives using the Gassner line approach and the experimentally observed lives lay in a band between $+30 \%$ and $-20 \%$ using the experimental data as reference. For the rotary friction welded specimens the equivalent values were $-8 \%$ and $+9 \%$. 


\section{References}

1. Sonsino CM, Heim R, Melz T. Lightweight-structural durability design by consideration of variable amplitude loading. International Journal of Fatigue. 2016;91:328-36.

2. DiMatteo ND. Fatigue and Fracture ASM International 1996 (5th printing, 2007).

3. Pook L. Metal Fatigue what it is, why it matters. Gladwell GML, editor. Dordrecht: Springer; 2007. 275 p.

4. $\quad$ Schütz W. A history of fatigue. Engineering Fracture Mechanics. 1996;54(2):263-300.

5. Maggiolini E, Benasciutti D, Susmel L, Hattingh DG, James MN, Tovo R. Friction stir welds in aluminium: Design S-N curves from statistical analysis of literature data. Fatigue \& Fracture of Engineering Materials \& Structures. 2018;41(11).

6. EN 1999-1-3:2007/A1. Eurocode 9: Design of aluminium structures - Part 1 - 3: Structures susceptible to fatigue: EUROPEAN COMMITTEE FOR STANDARDIZATION; 2007. p. 001 - 103.

7. IIW Document XIII - 1965-03 / XV-1127-03. Recommendations for Fatigue Design of Welded Joints and Components. Germany: International Institue of Welding; 2004. p. 001 146.

8. Schmicker D, Persson PO, Strackeljan J. Implicit Geometry Meshing for the simulation of Rotary Friction Welding. Journal of Computational Physics. 2014;270(0):478-89.

9. FALSTAFF Description of a fighter aircraft loading standard for fatigue evaluation. Emmen, Switzerland: Combined report of F\&W (Switzerland), LBF (Darmstadt), NLR (Amsterdam) and IABG (Munich).

10. Heuler P, Klätschke H. Generation and use of standardised load spectra and loadtime histories. International Journal of Fatigue. 2005;27(8):974-90.

11. Tsikayi DS. Friction hydro pillar riveting process of Ti-6Al-4V titanium sheet. Port Elizabeth: Nelson Mandela Metropolitan University; 2015.

12. Livingston JJ. The microstructural evolution and constitutive analysis for a physical simulation of friction stir processing of Ti-6Al-4V: Ohio State; 2011.

13. Kimura M, Seo K, Kusaka M, Fuji A. Observation of joining phenomena in friction stage and improving friction welding method. JSME International Journal Series A Solid Mechanics and Material Engineering. 2003;46(3):384-90.

14. Sonsino CM. Fatigue testing under variable amplitude loading. International Journal of Fatigue. 2007;29(6):1080-9.

15. Becker WT, Shipley RJ. Failure Analysis and Prevention: ASM International; 2002.

16. ASTM. E739-91 Standard Practice for Statistical Analysis of Linear Or Linearized Stress-Life (S-N) and Strain-Life $(\epsilon-N)$ Fatigue Data. West Conshohocken: ASTM International; 1991 (Reapproved 1998).

17. Jia Yu GM, Timo Björk. Development of data sheets for statistical evaluatin of fatigue data. Journal of iron and steel research international. 2011;Mechanical Engineering:103.

18. Peters J, Janvier E, Lütjering G, editors. Role of crack front geometry on fatigue crack propagation resistance and fracture toughness of titanium alloys. In: Proceedings of the 8th International Fatigue Congress Stockholm, Sweden EMAS; 2002. 
NOTE: ALL IMAGES \& TABLES COLOUR FOR ONLINE COPY AND GRAYSCALE FOR PRINT

Table 1: Alloy composition in wt\% and mechanical properties for $\mathrm{D}=14 \mathrm{~mm}$ bar.

\begin{tabular}{|c|c|c|c|c|c|c|c|c|c|c|}
\hline $\mathrm{C}$ & $\mathrm{N}$ & $\mathrm{Al}$ & $\mathrm{Fe}$ & $\mathrm{V}$ & $\mathrm{H}$ & $\mathrm{O}$ & $\mathrm{Ti}$ & $\begin{array}{c}\sigma_{0.2 \%} \\
\mathrm{MPa}\end{array}$ & $\begin{array}{c}\text { UTS } \\
\mathrm{MPa}\end{array}$ & $\begin{array}{c}\text { Elongation } \\
\text { 4D\% }\end{array}$ \\
\hline 0.010 & 0.01 & 6.06 & 0.15 & 3.99 & 0.0036 & 0.112 & Bal. & 886 & 985 & 23.4 \\
\hline
\end{tabular}

Table 2: Weld matrix

\begin{tabular}{|c|c|c|}
\hline \multicolumn{2}{|l|}{ Weld Specimens } \\
\hline Designation & rpm & upset \\
\hline $\mathrm{H} 4 ; \mathrm{H} 4 \mathrm{t}$ & 2500 & 1.5 \\
\hline $\mathrm{H} 5 ; \mathrm{H} 5 \mathrm{t}$ & 3500 & 1.5 \\
\hline $\mathrm{H} 6 ; \mathrm{H} 6 \mathrm{t}$ & 5000 & 1.5 \\
\hline $\mathrm{H} 7$ & 3500 & 0.5 \\
\hline $\mathrm{H} 9$ & 3500 & 1 \\
\hline
\end{tabular}

Table 3: Mechanical properties of material

\begin{tabular}{|l|c|c|}
\hline & Parent alloy & Welded specimen \\
\hline Ultimate tensile strength$^{\star}$ [MPa] & 1029 & 1143 \\
\hline Yield strength* ${ }^{\text {[MPa] }}$ & 901 & 1051 \\
\hline
\end{tabular}

${ }^{*}$ Average values of three tensile test results

Table 4: $D_{\text {real }}$ results

\begin{tabular}{|l|c|c|c|c|c|c|c|}
\hline Designation & $\begin{array}{c}\text { Max } \\
\text { stress } \\
\text { amplitude } \\
\text { [MPa] }\end{array}$ & $\begin{array}{c}\text { Damage } \\
\text { sum in } L \text { s } \\
\text { cycles } \\
\boldsymbol{D}_{\text {spec }}\end{array}$ & $\begin{array}{c}\text { Calculated } \\
\text { number of } \\
\text { sequence } \\
\text { blocks } \\
\left(\boldsymbol{D}_{\text {real }} \mathbf{1}\right)\end{array}$ & $\begin{array}{c}\text { Calculated } \\
\text { life in } \\
\text { cycles } \\
\overline{\boldsymbol{N}}_{\text {calc }}\end{array}$ & $\begin{array}{c}\text { Experimental } \\
\text { life in cycles } \\
\overline{\boldsymbol{N}}_{\text {exper, }}\end{array}$ & $\boldsymbol{D}_{\text {real }}$ & $\begin{array}{c}\text { Difference } \\
\text { in life } \\
\%\end{array}$ \\
\hline Parent 30 kN & 1061 & 0.000607 & 1647.48 & 5271949 & 2450000 & $\mathbf{0 . 4 6}$ & $\mathbf{- 1 1 5 \%}$ \\
\hline Parent 32 kN & 1132 & 0.007372 & 135.65 & 434083 & 320000 & $\mathbf{0 . 7 4}$ & $\mathbf{- 3 6 \%}$ \\
\hline H3731 kN & 1096 & 0.003250 & 307.69 & 984609 & 544000 & $\mathbf{0 . 5 5}$ & $\mathbf{- 8 1 \%}$ \\
\hline H3732 kN & 1132 & 0.005437 & 183.92 & 588528 & 275200 & $\mathbf{0 . 4 7}$ & $\mathbf{- 1 1 4 \%}$ \\
\hline
\end{tabular}


Table 5: Corrected lifetime prediction results

\begin{tabular}{|l|c|c|c|c|c|c|}
\hline Designation & $\begin{array}{c}\text { Max stress } \\
\text { amplitude } \\
\text { [MPa] }\end{array}$ & $\begin{array}{c}\text { Damage } \\
\text { sum in } L \text { s } \\
\text { cycles } \\
\boldsymbol{D}_{\text {spec }}\end{array}$ & $\begin{array}{c}\text { Calculated } \\
\text { number of } \\
\text { sequence } \\
\text { blocks } \\
\boldsymbol{D}_{\text {real }} \mathbf{0 . 6 0} \text { or } \\
\mathbf{0 . 5 1})\end{array}$ & $\begin{array}{c}\text { Calculated } \\
\text { life in } \\
\text { cycles } \\
\overline{\boldsymbol{N}}_{\text {calc }}\end{array}$ & $\begin{array}{c}\text { Experimental } \\
\text { life in cycles } \\
\overline{\boldsymbol{N}}_{\text {exper, }}\end{array}$ & $\begin{array}{c}\text { Difference } \\
\text { in life } \\
\%\end{array}$ \\
\hline Parent 30 kN & 1061 & 0.000607 & 988.49 & 3163170 & 2450000 & $\mathbf{- 2 9 \%}$ \\
\hline Parent 32 kN & 1132 & 0.007372 & 81.39 & 260450 & 320000 & $\mathbf{1 9 \%}$ \\
\hline H37 31 kN & 1096 & 0.003250 & 156.92 & 502151 & 544000 & $\mathbf{8 \%}$ \\
\hline H37 32 kN & 1132 & 0.005437 & 93.80 & 300149 & 275200 & $\mathbf{- 9 \%}$ \\
\hline
\end{tabular}

Table 6: CA tabulated fatigue results

\begin{tabular}{|c|c|c|c|c|}
\hline Designation & $\begin{array}{c}\text { Stress } \\
\text { amplitude } \\
\text { MPa }\end{array}$ & $\begin{array}{c}\text { Fatigue life } \\
\boldsymbol{N}_{\boldsymbol{f}}\end{array}$ & Remarks & Crack initiation site \\
\hline \multicolumn{5}{|c|}{ Parent specimens @ R=-1 } \\
\hline P1 & 636.62 & 2003068 & run out & NA \\
\hline P5 & 702.93 & 30299 & failed & parent surface \\
\hline P7 & 689.67 & 17050 & failed & parent surface \\
\hline P8 & 663.15 & 110466 & failed & parent surface \\
\hline P9 & 689.67 & 16951 & failed & parent surface \\
\hline P10 & 663.15 & 112709 & failed & parent surface \\
\hline P14 & 702.93 & 15572 & failed & parent surface \\
\hline P15 & 680.83 & 52242 & failed & parent surface \\
\hline Welded specimens @ R=-1 & 663.15 & 26207 & failed & parent surface \\
\hline H39 & 565.88 & 57164 & failed & HAZ surface \\
\hline H53 & 565.88 & 77552 & failed & parent surface \\
\hline H42 & 663.15 & 18282 & failed & HAZ surface \\
\hline H38 & 530.52 & 2001421 & run out & NA \\
\hline H36 & 618.94 & 46038 & failed & HAZ surface \\
\hline H51 & 618.94 & 45384 & failed & HAZ surface \\
\hline H35 & 548.20 & 121360 & failed & parent surface \\
\hline H29 & &
\end{tabular}


Table 7: VA tabulated fatigue results

\begin{tabular}{|c|c|c|c|c|c|c|}
\hline Designation & $\begin{array}{c}\text { Max stress } \\
\text { MPa }\end{array}$ & $\begin{array}{c}\text { Max } \\
\text { load } \\
\text { level } \\
\text { kN }\end{array}$ & $\begin{array}{c}\text { Fatigue } \\
\text { life } \\
\mathbf{N}_{f}\end{array}$ & $\begin{array}{c}\text { No. of } \\
L_{s} \\
\text { repeats }\end{array}$ & Remarks & Crack initiation site \\
\hline Parent specimens \\
\hline PF1 & 1000.91 & 28.30 & 2450000 & 765 & failed & parent surface \\
\hline PF2 & 1114.08 & 31.50 & 320000 & 100 & failed & parent surface \\
\hline PF3 & 1061.03 & 30.00 & 406400 & 127 & failed & parent surface \\
\hline PF4 & 1103.47 & 31.20 & 345600 & 108 & failed & parent surface multi sites \\
\hline PF5 & 930.17 & 26.30 & 2976000 & 930 & run out & NA \\
\hline PF6 & 983.22 & 27.80 & 2294400 & 717 & failed & parent surface \\
\hline PF7 & 1036.28 & 29.30 & 1263600 & 394 & failed & parent surface multi sites \\
\hline PF8 & 1068.11 & 30.20 & 579200 & 181 & failed & parent surface \\
\hline Welded specimens & & & & \\
\hline H41 & 1015.05 & 28.70 & 3126400 & 977 & run out & NA \\
\hline H32 & 1082.25 & 30.60 & 275200 & 86 & failed & HAZ surface \\
\hline H34 & 1085.79 & 30.70 & 544000 & 170 & failed & parent surface \\
\hline H44 & 1018.59 & 28.80 & 3200000 & 1000 & run out & NA \\
\hline H50 & 1071.64 & 30.30 & 1366400 & 427 & failed & HAZ surface \\
\hline H18 & 1071.64 & 30.30 & 416000 & 130 & failed & weld surface multi sites \\
\hline H31 & 1099.94 & 31.10 & 214400 & 67 & failed & weld surface \\
\hline H45 & 1078.72 & 30.50 & 425600 & 133 & failed & HAZ surface multi sites \\
\hline
\end{tabular}




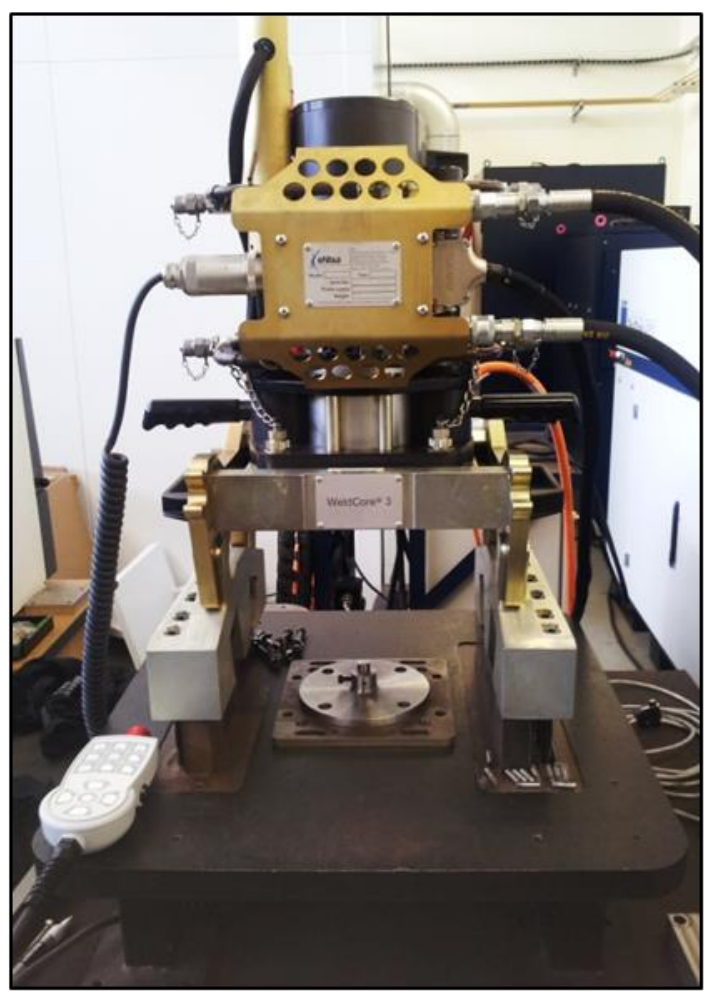

Figure 1: WeldCore 3 friction processing platform.

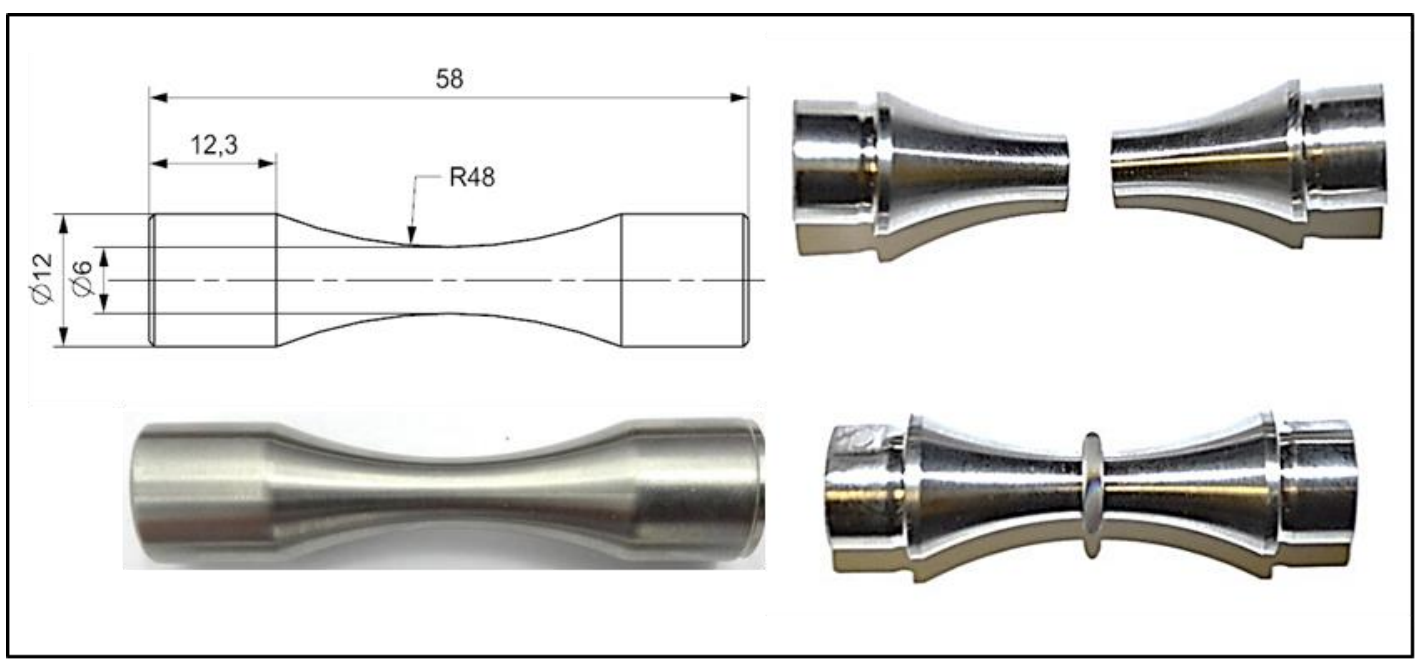

Figure 2: Specimen geometry and RFW joint. 


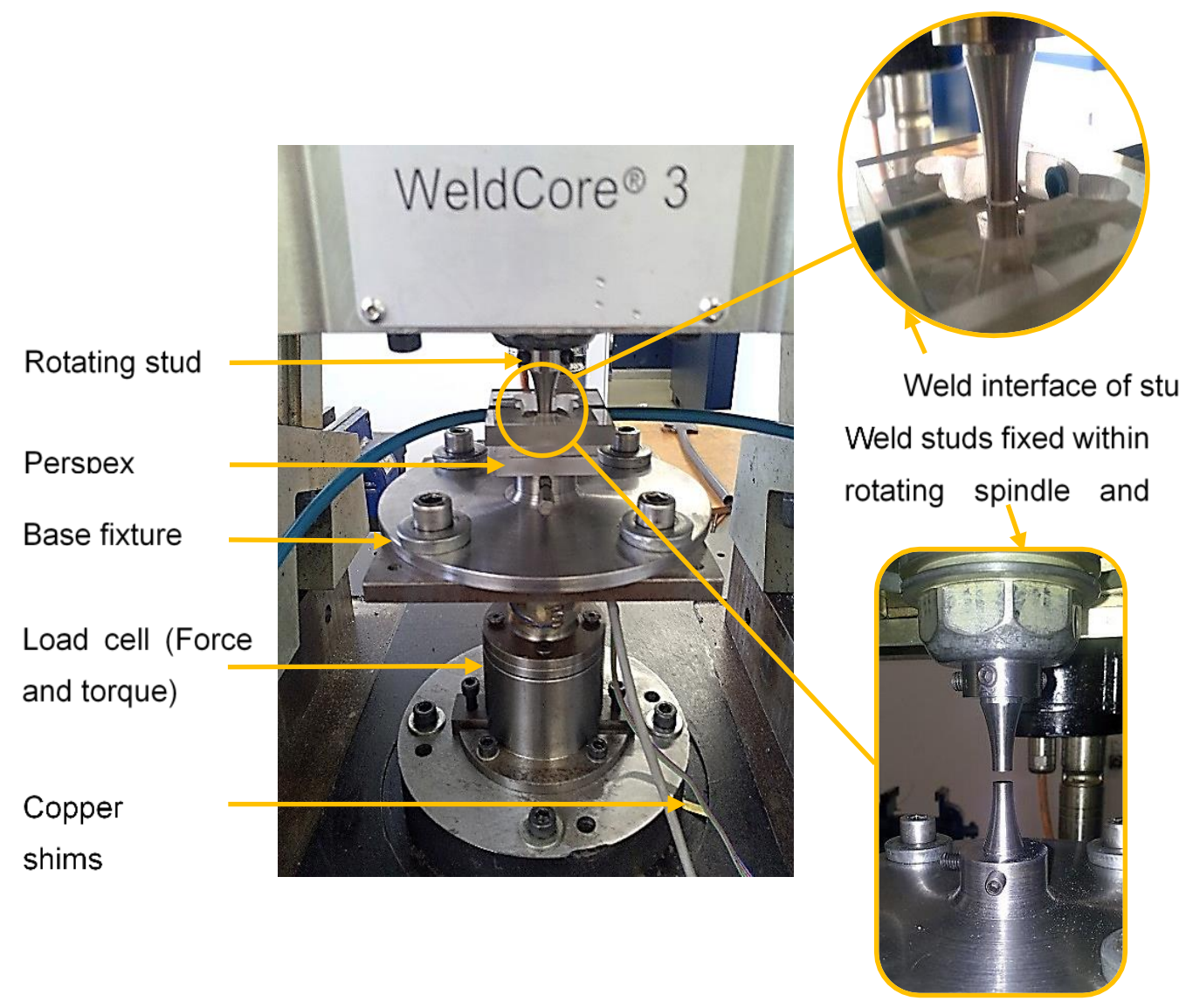

Figure 3: Welding arrangement for the fatigue specimens.

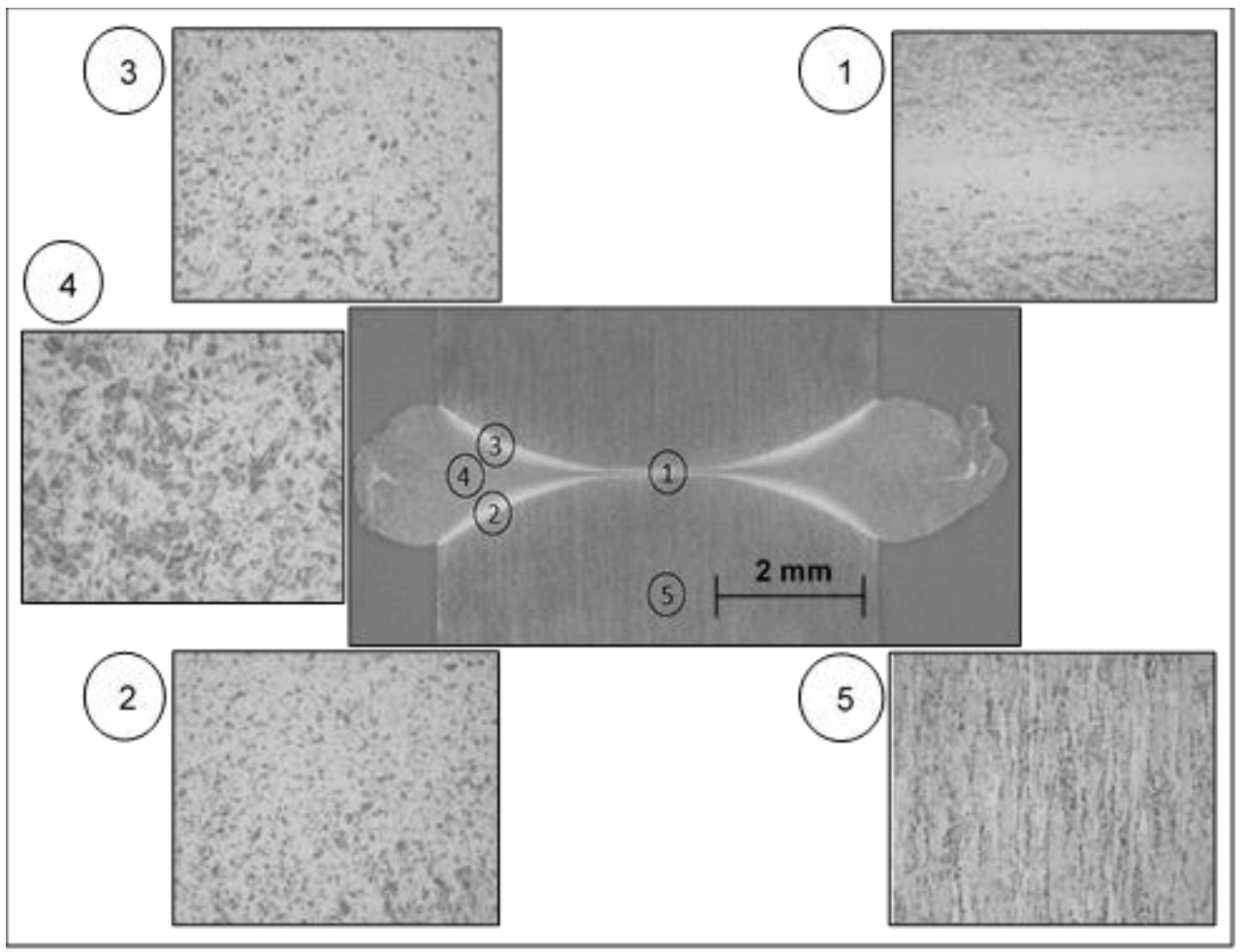

Figure 4: Macro-section across the weld and microstructures at selected positions. 


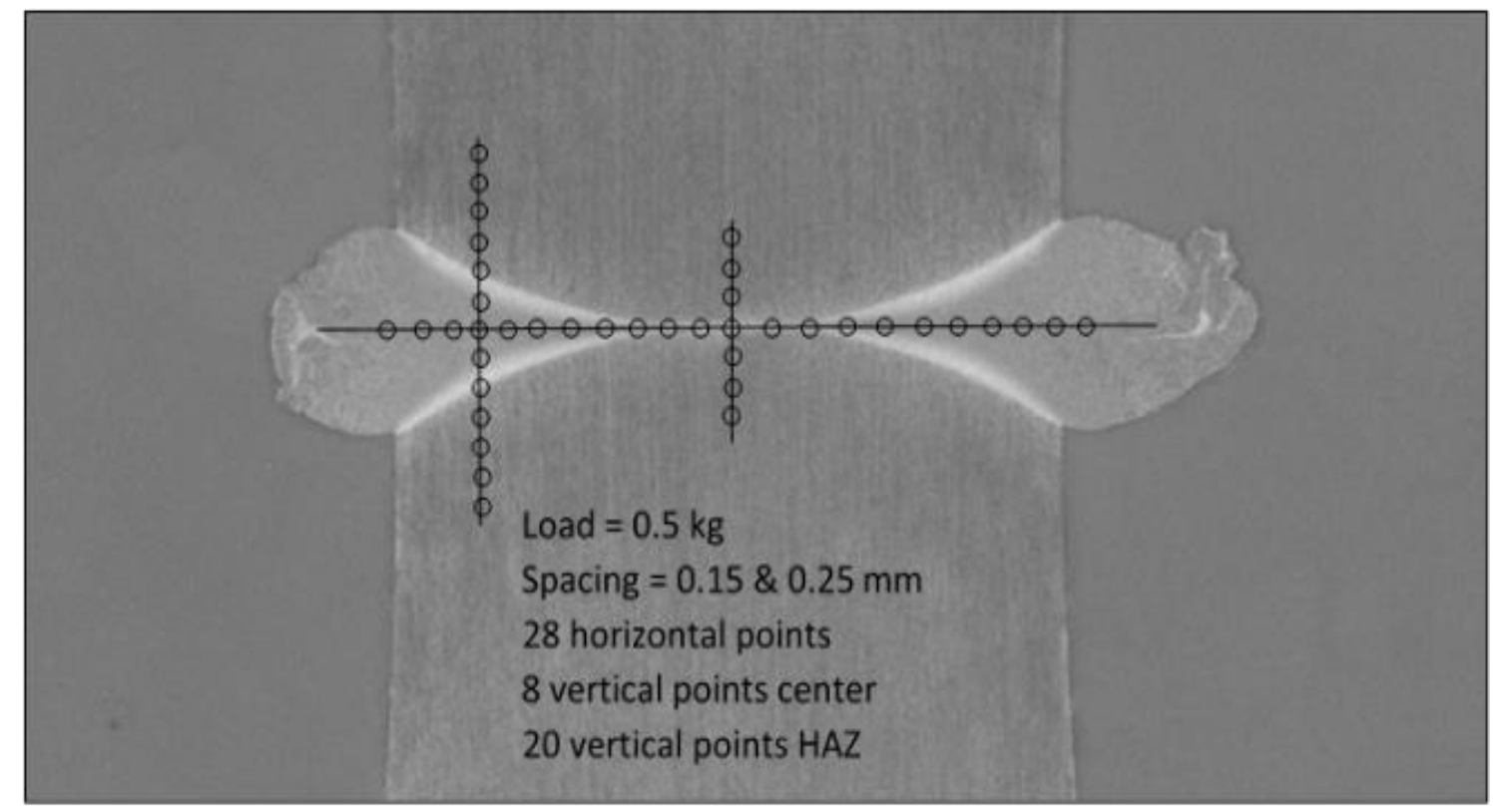

Figure 5: Positions where microhardness measurements were made in a typical welded specimen

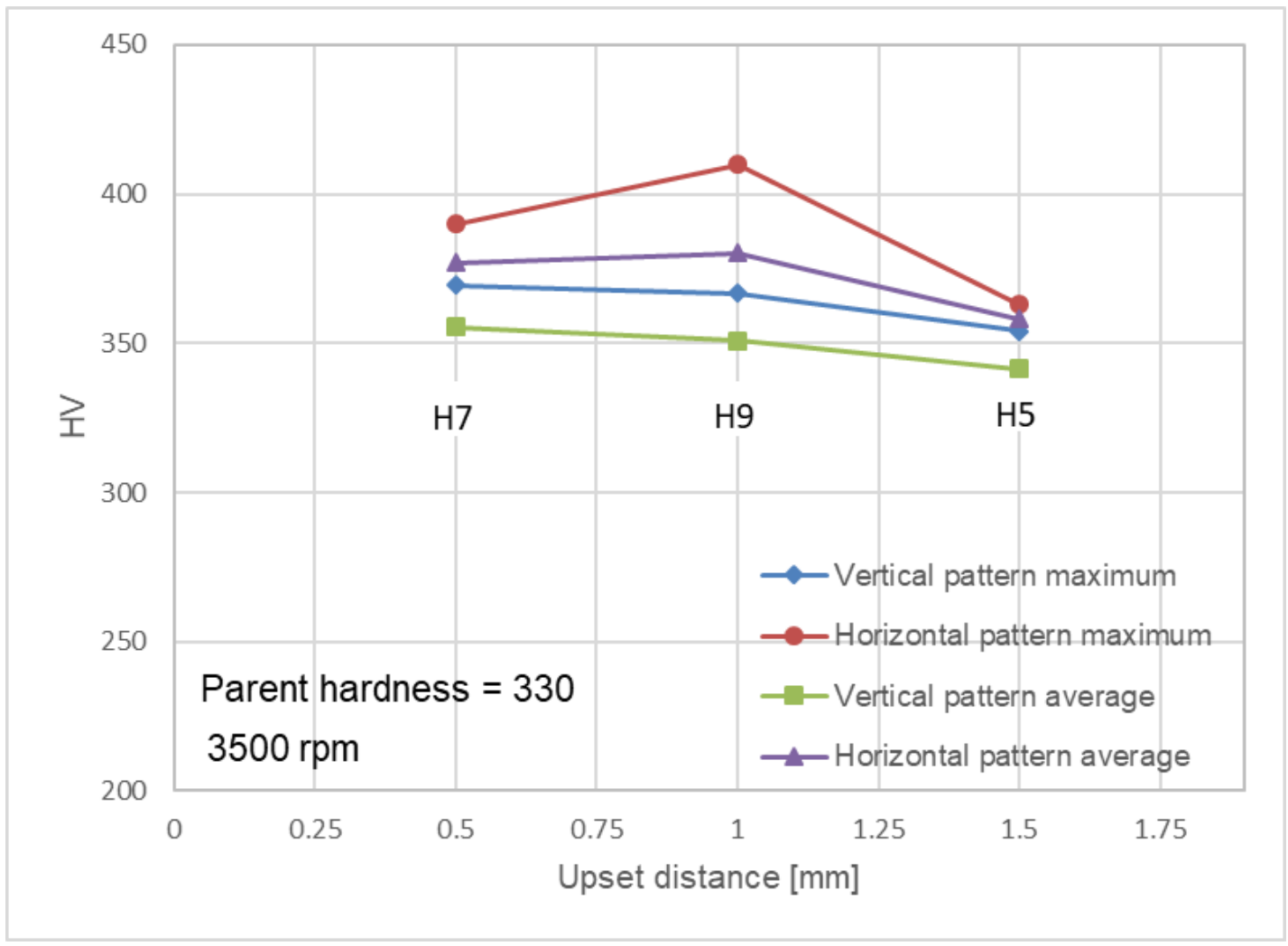

Figure 6: Upset distance parameter hardness data. 


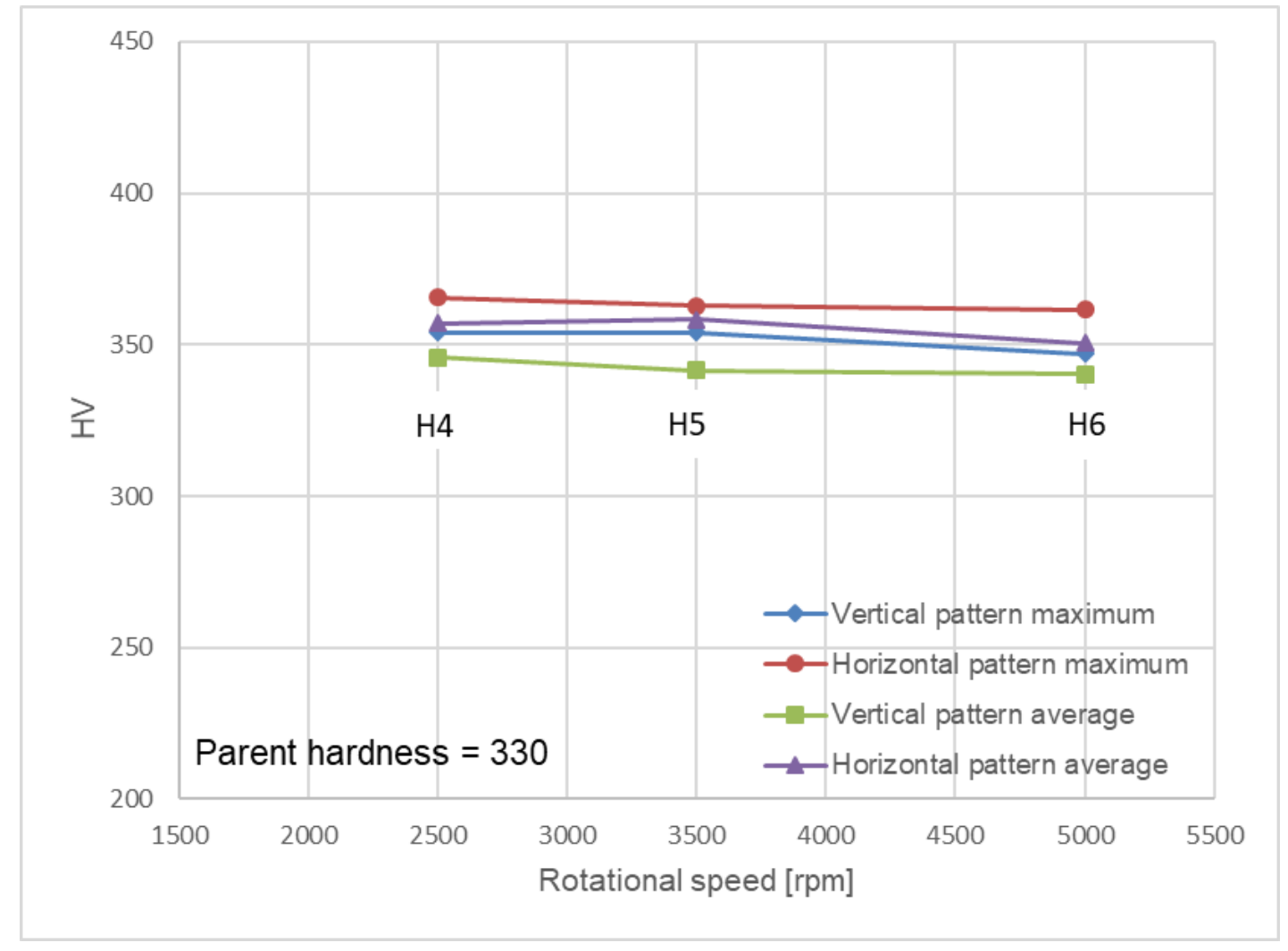

Figure 7: Rotational speed parameter hardness data.

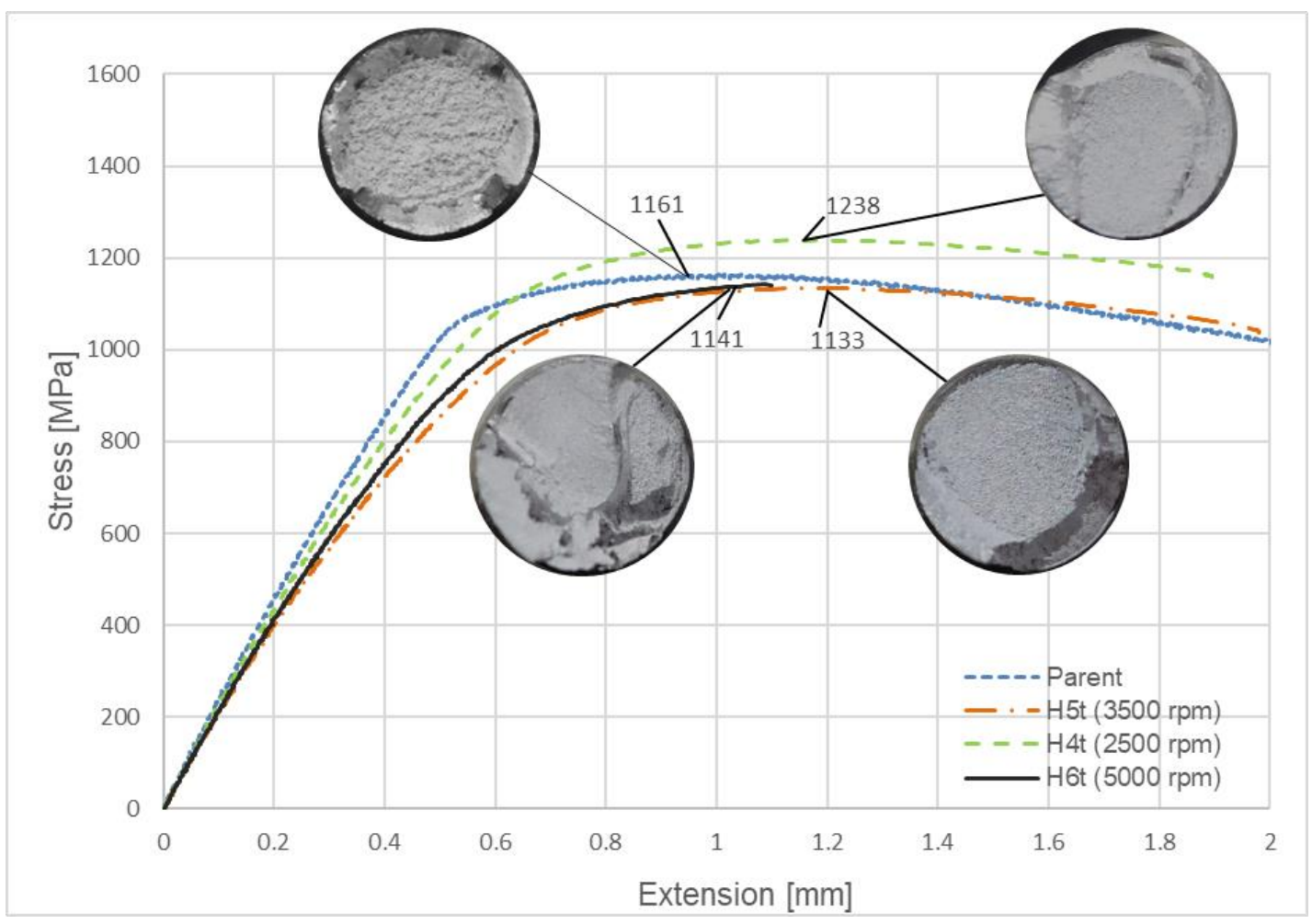

Figure 8: Tensile test results for repeat welds corresponding to the parameters used with trials $\mathrm{H} 4, \mathrm{H} 5$ and $\mathrm{H} 6$. 


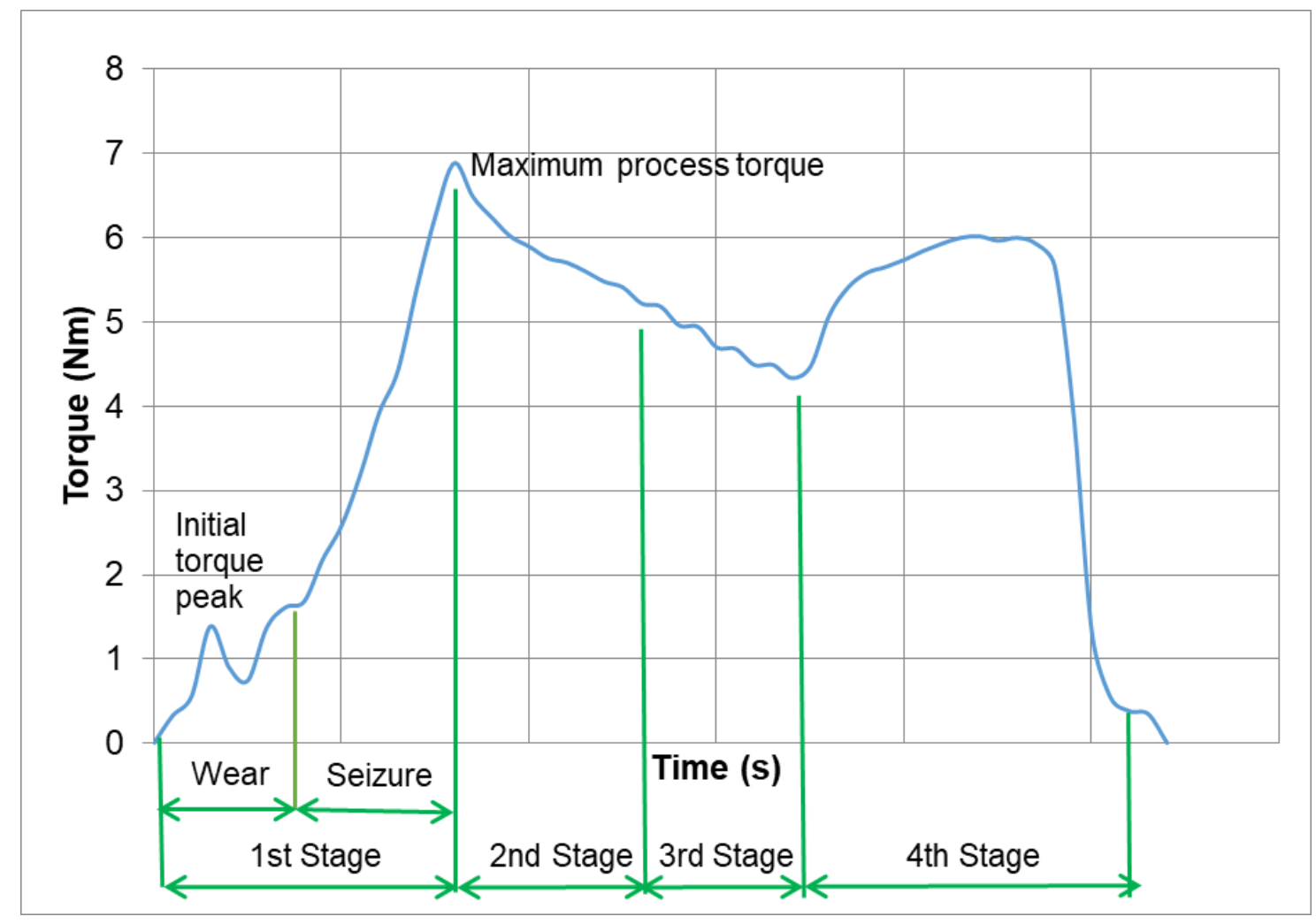

Figure 9: Typical torque curve measured during welding with the chosen process parameters.

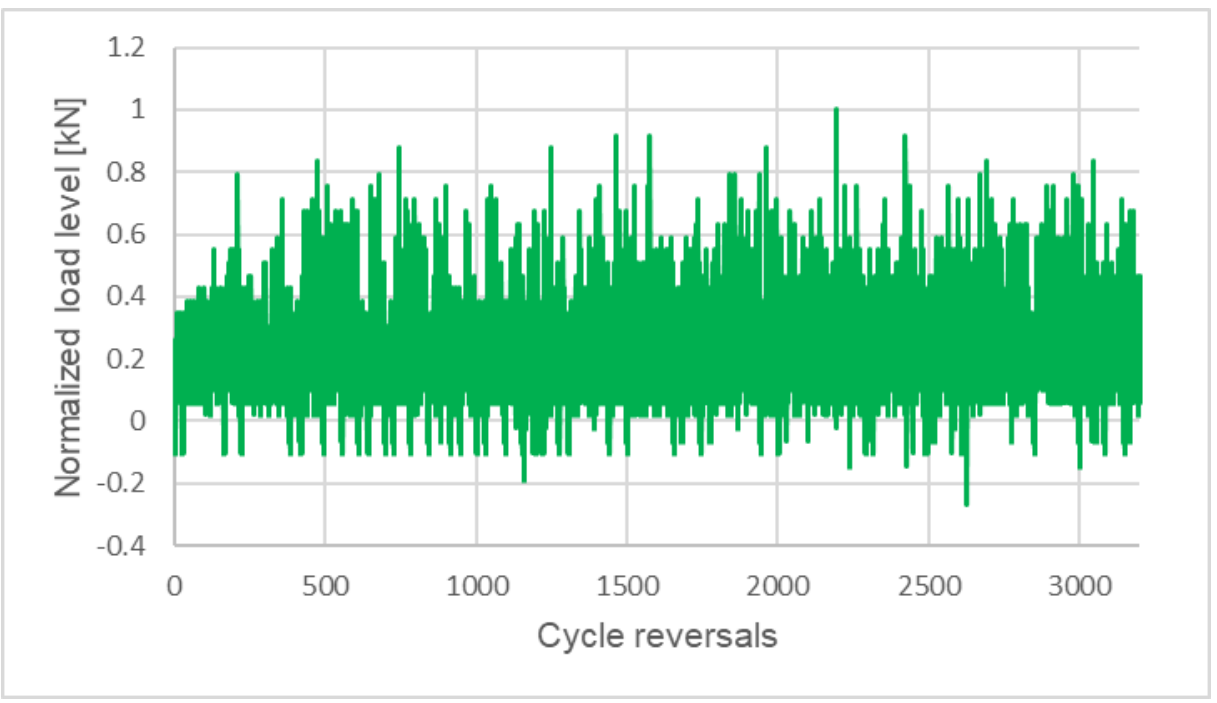

Figure 10: Extract of mini-FALSTAFF load history used in the VA testing ( $L s=3,200)$. 


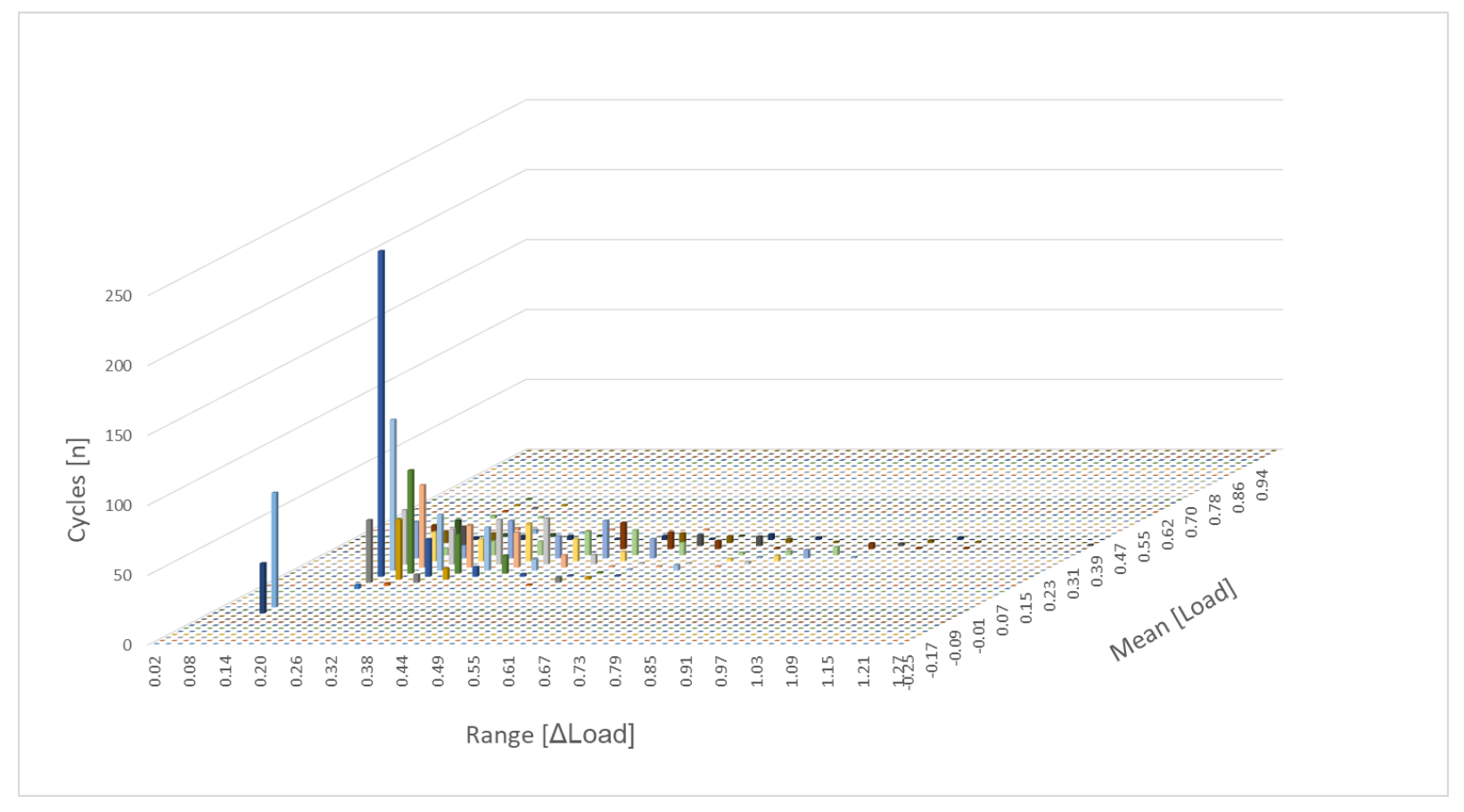

Figure 11: Mini-FALSTAFF Rainflow Matrix 


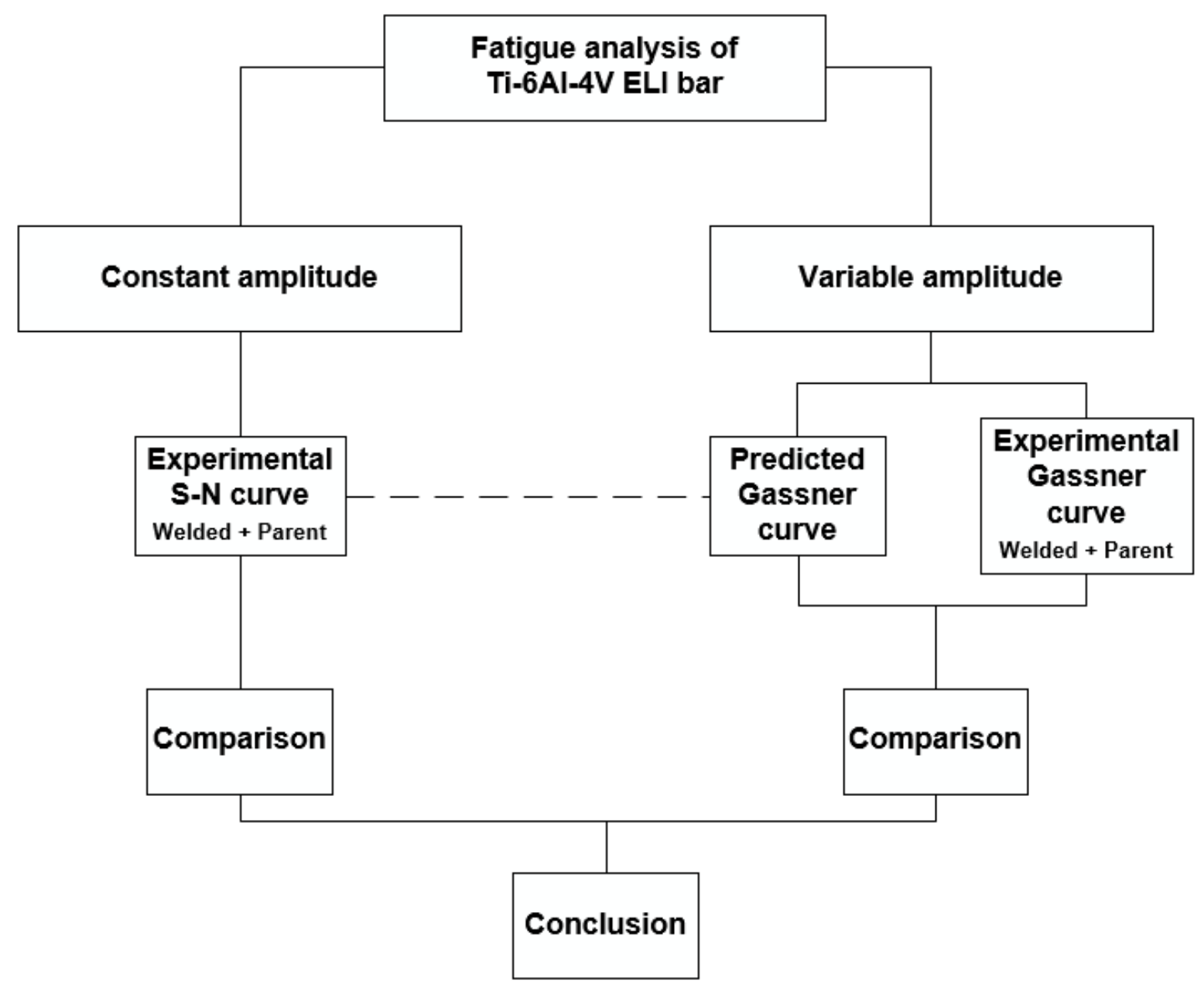

Figure 12: Fatigue analysis approach 


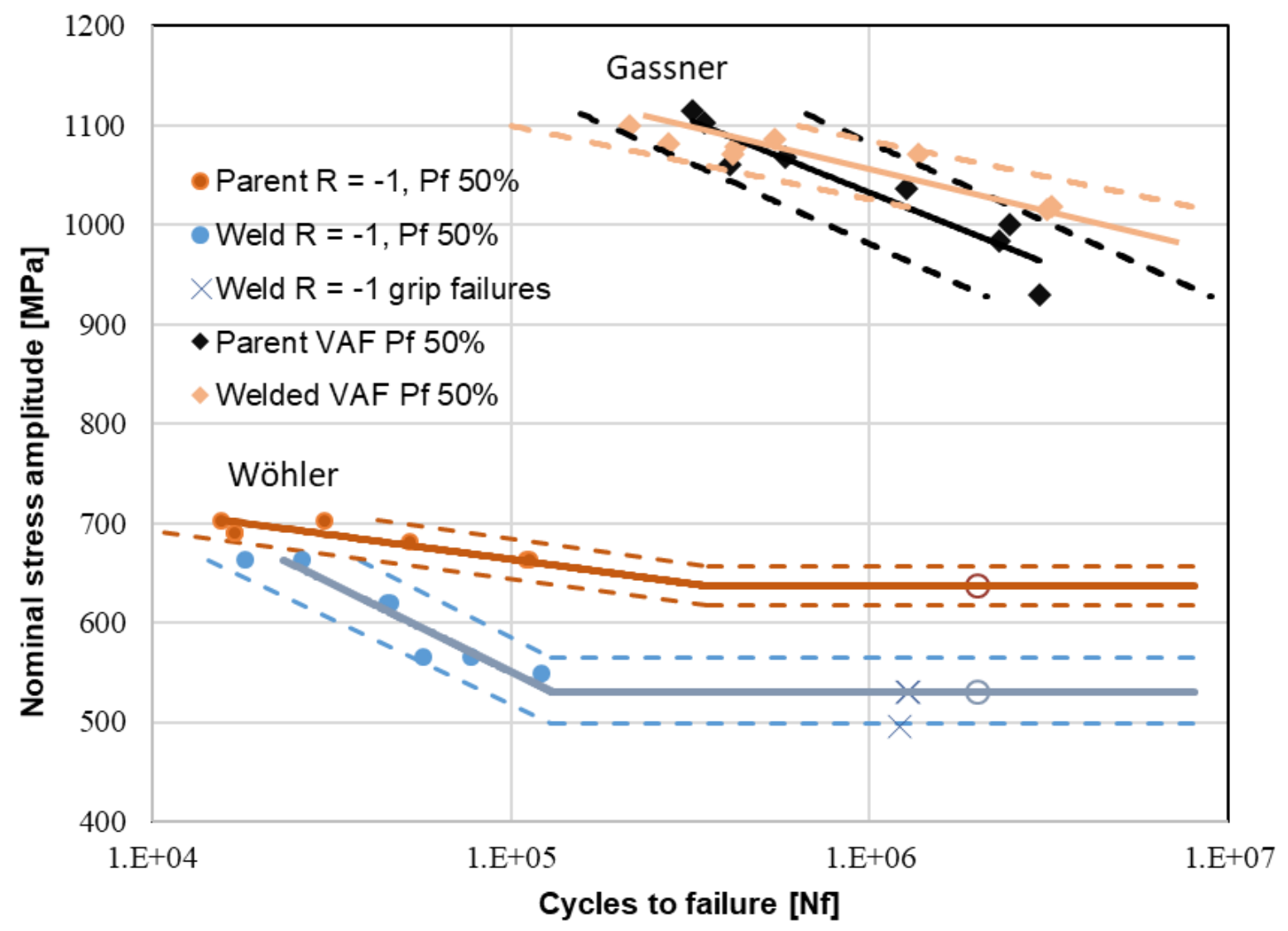

Figure 13: Fatigue results under CA (Wöhler curve) and VA (Gassner line) loading for the parent alloy and the rotary friction welds. The lower dashed lines represent a $10 \%$ probability of failure and the upper dashed lines a $90 \%$ probability.

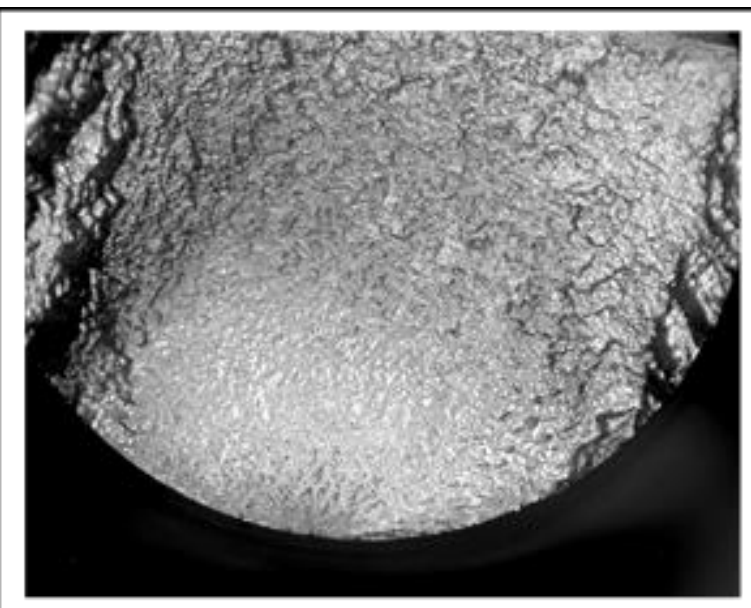

$\mathrm{P} 8 \times 25$

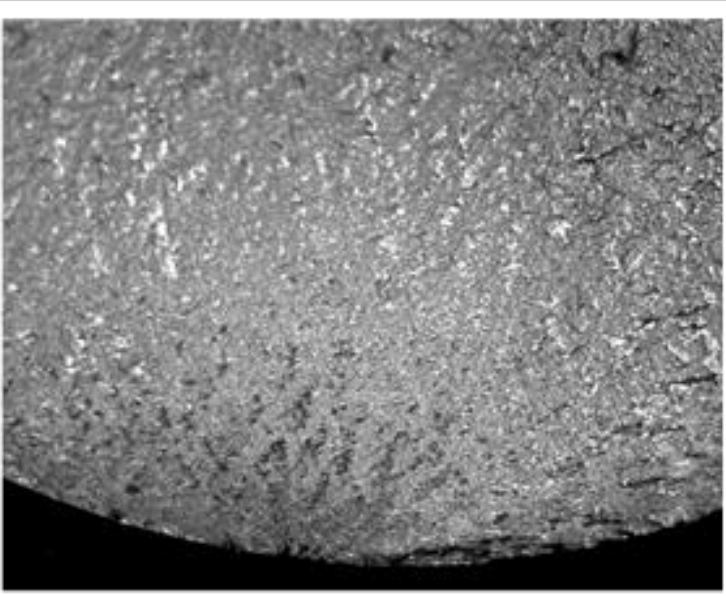

P8 $\times 60$

Figure 14: Parent specimen CA fracture surface 


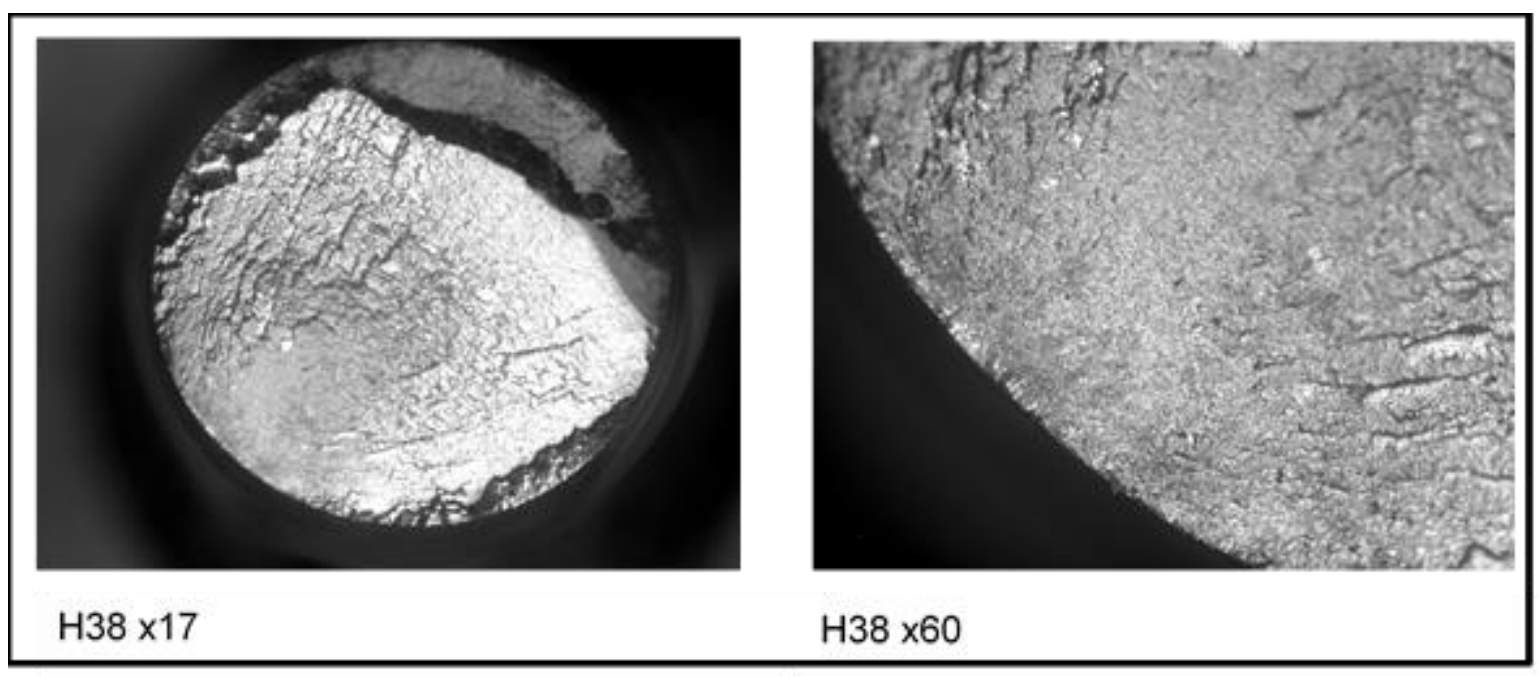

Figure 15: Welded specimen CA fracture surface

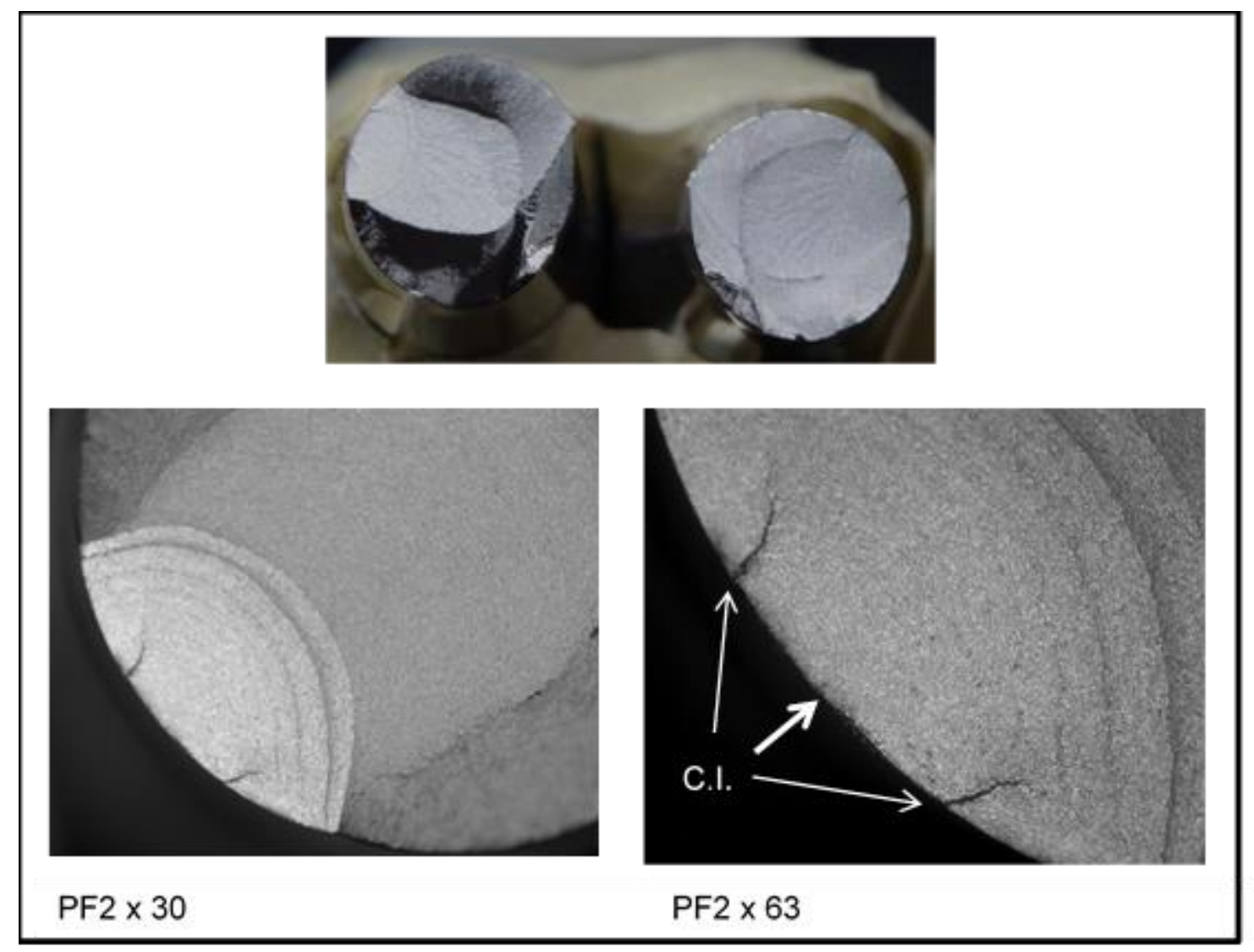

Figure 16: Parent specimen VA fracture surface 


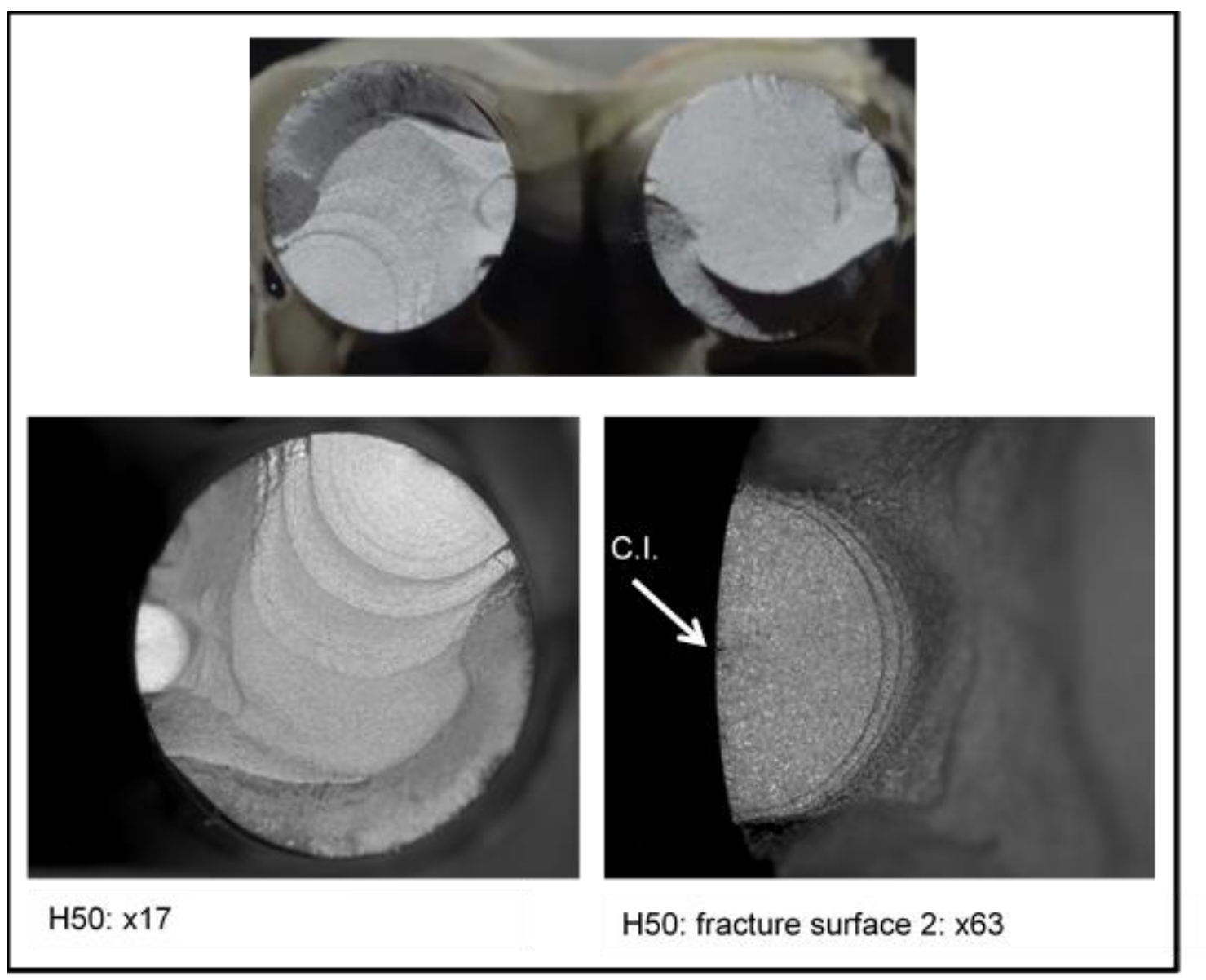

Figure 17: Welded specimen VA fracture surface 


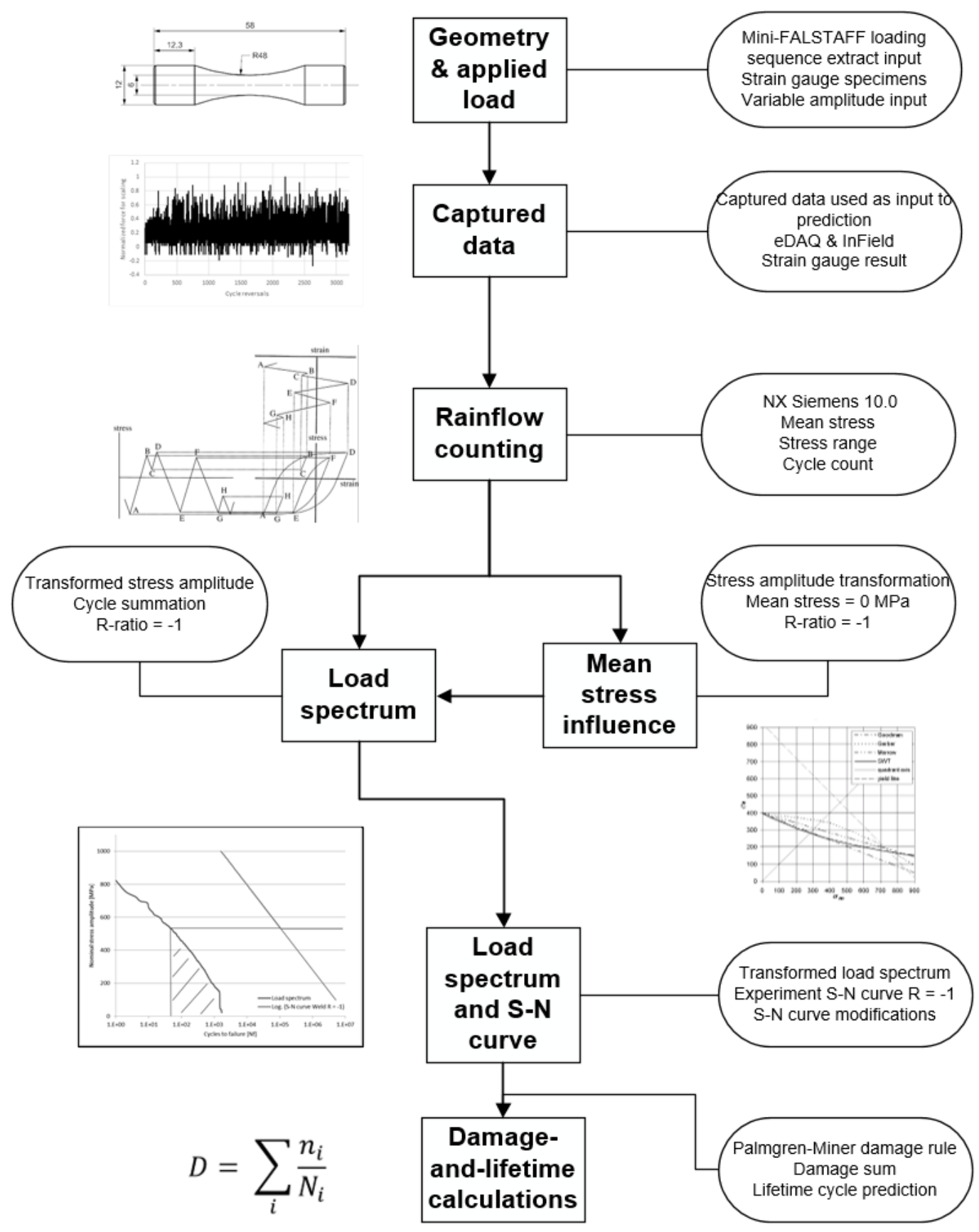

Figure 18: Schematic illustration of the VA life prediction model used in the present work. 


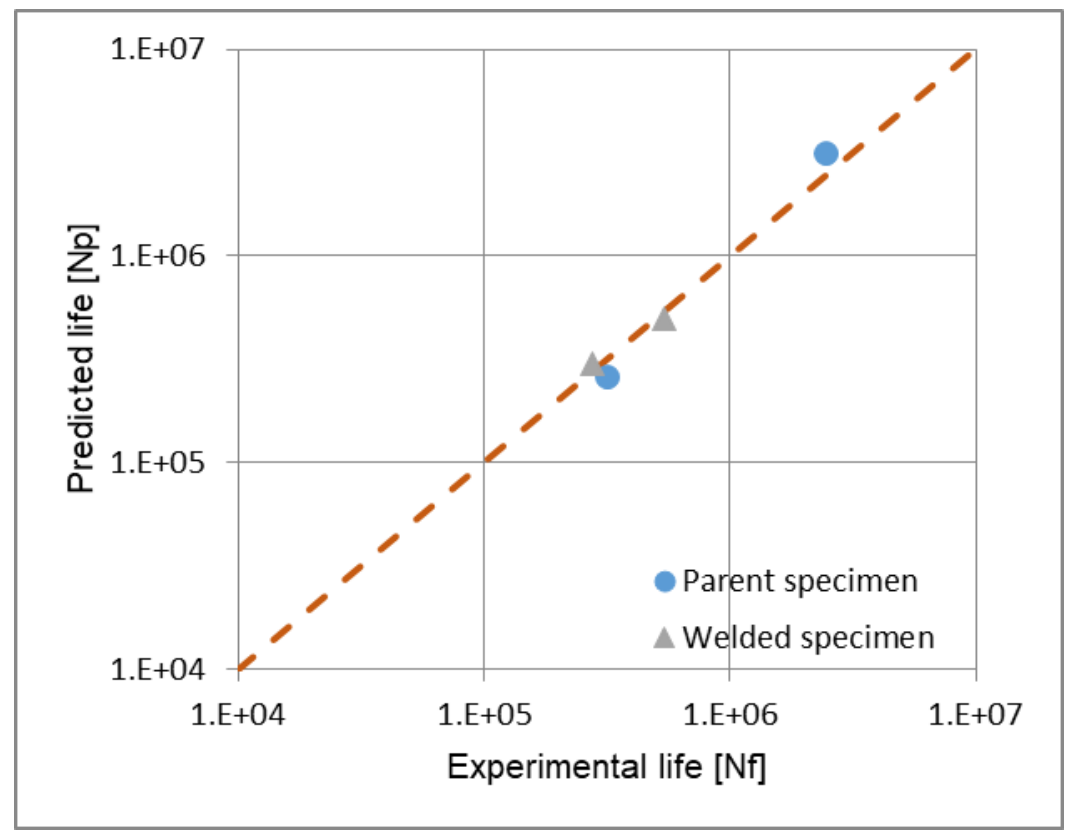

Figure 19: Correlation between predicted and experimental VA fatigue lives. 